\title{
FORECASTING THE DISTRIBUTION OF PRECIPITATE DIAMETERS IN THE PRESENCE OF CHANGES IN THE STRUCTURE OF THE MATERIAL
}

\begin{abstract}
The results of investigations on the microstructure of T23 and T24 low-alloy steels as well as P91 and P92 high-chromium steels in the as-received condition and after $70.000 \mathrm{~h}$ annealing at $550-650^{\circ} \mathrm{C}$ are presented. The quantitative analysis of the existing precipitates was performed for representative images of microstructure. The statistical analysis of collected data allowed the parameters of a selected theoretical statistical distribution to be estimated. A forecast of average precipitate diameter and standard deviation of such a distribution for the time of 100,000 hours at 550 and $600^{\circ} \mathrm{C}$ for T23 and T24 steels and at 600 and $650^{\circ} \mathrm{C}$ for P91 and P92 steels was calculated. The obtained results of investigations have made it possible to compare changes in the microstructure of various steel grades due to long-term impact of elevated temperature. They have also confirmed the possibility of using, in evaluating the degradation degree of materials in use, the forecasting methods that derive from mathematical statistics, in particular the theory of stochastic processes and forecast by analogy methods. The presented approach allows the development of a forecast of precipitate diameter probability density under the microstructure instability conditions for selected steel grades. The assessment of material condition that takes into consideration, but is not limited to, the precipitate diameter measurement is useful as an assessment component in estimating the time of safe service of power unit elements working under creep conditions.
\end{abstract}

Keywords: microstructure, precipitates, statistics, forecasting, ageing

\section{Introduction}

To estimate the exhaustion degree of the examined steels based on changes in their microstructure, it is necessary to understand the behaviour of the materials at elevated temperature over a long time of exposure [1-5]. The long-term investigations that are being carried out indicate that changes in the microstructure of steel take place in the basic phase components, resulting in the loss of service life, and thus determining their suitability for further service. The contribution of individual processes and their intensity in the loss of life depends on the structure in the as-received condition and working temperature [6-10].

The subject of the article is the application of statistical approach to precipitate diameter forecasting for each distribution parameter (not only the average). The observation of the structure of materials leads to a conclusion that traditional theories do not reflect the high degree of complexity and heterogeneity of real materials. Such materials may have a common feature: the existence of the microstructure that is unique. It can be concluded that the image of the microstructure is highly complex and characterized by randomness. Its description should therefore apply to specific mathematical methods to assume the randomness and complexity. Mathematical statistics meets such conditions.

The above-mentioned approach may be treated as a verification of and supplement to models derived from the theory of thermodynamics, which describes development of the carbide precipitation process in steels. The basic models include [11]:

- average precipitate radius approximation,

- Euler approximation for multiple classes of precipitates,

- Lagrange approximation for multiple classes of precipitates.

They allow the quantitative description of the development of precipitates over time including the geometric parameters of precipitates.

\section{Methodology}

The microstructural investigations were carried out with a scanning electron microscope (SEM) on conventionally prepared nital-etched metallographic microsections. The quantitative analysis of precipitates was carried out using the image analysis system. The image analysis system was calibrated using the scale marker placed in structure images. The calibration

\footnotetext{
* INSTITUTE OF FERROUS METALLURGY, 12-14 K. MIARKI STR., 44-100 GLIWICE, POLAND

** CZESTOCHOWA UNIVERSITY OF TECHNOLOGY, INSTITUTE OF MATERIALS ENGINEERING, 19 ARMII KRAJOWEJ AV., 42-200 CZĘSTOCHOWA, POLAND

Corresponding author: azielinski@imz.pl
} 
coefficient was: 1 pixel $=0.040 \mu \mathrm{m}$. The measuring frame of $1020 \times 940$ pixels was applied to every analyzed image .

Statistical analysis of collected data with the aim of estimating the parameters of selected theoretical statistical distribution, followed by the calculation of a forecast of the expected value and standard deviation of such a distribution, was made for the future time of service. Finally, a forecast for the entire distribution was made based on the assumption that it took the form of a log-normal distribution.

The data set was obtained from a few moments. Thus, the analysis of stochastic processes, which are probabilistic models of time-dependent phenomena that occur in reality, needs to be referred to $[12,13]$. The database, including data based on which the statistical inference is conducted, is formed by the results of random samples from considered moments. If only one stochastic process realization is available, we deal with a time series. Statistical inference is easier when stochastic processes are characterized by stationary and ergodicity properties. 'Stationary of a process' means that the expected value and variance are constant over time, whereas its ergodicity means that extrapolation of the past in the system is a reliable indication for the future, and this means that the structure of this system remains stable over time. Thus, a change is perceived as a continuous movement towards a present result where the sequence of events produces no real effects and has no qualitative impact on structure of the system. Dynamic changes always result in a stable general equilibrium, regardless of at what point the process started. In case of a lack of ergodicity properties, it is necessary to change the approach to the problem and forecast (inference into future) that repeals the classical assumptions adopted in the theory of prediction, i.e.:

- $\quad$ knowledge of the evolution model for the forecast variable,

- stability of the examined regularity over time,

- $\quad$ stability of the distribution of the model's random component, knowledge of the values of the model's explanatory, variables within the period for which the forecast is being made,

- $\quad$ acceptability of model extrapolation beyond the variability area of explanatory variables observed in the 'sample'.

In a non-ergodic system, knowledge of the future, regardless of how complete it is, does not provide indications sufficient to determine probability distributions describing the system structure based on which future events will be generated.

The article presents the results for selected grades (lowalloy steel, about $2.5 \% \mathrm{Cr}$ and $9 \% \mathrm{Cr}$ steel) using the proposed methodology, which allows to take into account the effect of a structural change in the material. The theoretical form of the probability density function was selected to be the log-normal distribution, which is given by the following formula [14]:

$$
p(x)=\frac{1}{x \sigma \sqrt{2 \pi}} e^{(-\ln x-\mu)^{2} / 2 \sigma^{2}}
$$

The distribution parameters, i.e. the mean of logarithms of analyzed variables $(\mu)$ and the standard deviation of logarithms of variables $(\sigma)$, were estimated by the maximum likelihood method. The calculated log-normal distribution parameters became the basis for estimation of parameters of the linear regression function in the form of:

$$
\ln y_{i} \mid t=\beta_{0}+\beta_{1} t+u_{i}
$$

where $y_{i}-i$-th observation of dependent variable, $u_{i}-i$-th disruption of the random component, $\beta_{0}, \beta_{1}$ - unknown parameters, $t$-time, which was used to make a forecast for the future time of service [15-18].

\section{Results}

\section{Microstructure}

For T23 and T24 low-alloy steels and for P91 and P92 high-chromium steels the investigations of microstructure were carried out both in the as-received condition and after long-term annealing of up to $70.000 \mathrm{~h}$. The annealing was conducted at two temperature levels. For low-alloy steels the temperature of annealing was $550^{\circ} \mathrm{C}$ and $600^{\circ} \mathrm{C}$ and for $\mathrm{P} 91$ and $\mathrm{P} 92$ high-chromium steels it was $600^{\circ} \mathrm{C}$ and $650^{\circ} \mathrm{C}$. The annealing was conducted with an accuracy of up to $\pm 1^{\circ} \mathrm{C}$. For the above-mentioned assumed material conditions 10 to 15 images of microstructure at a magnification of $2000 \times$ were recorded. The examples of microstructure images in the as-received condition and after longterm annealing of $70.000 \mathrm{~h}$ are shown in Figures 1 through 3.

The images of recorded microstructures were used to carry out the quantitative analysis of the diameter of precipitates which occur mainly at the former austenite grain boundaries and bainite laths for T23 and T24 low-alloy steels and at the former austenite grain boundaries and martensite laths for P91 and P92 high-chromium steels. The basic statistical measures that describe the data set structure are presented in Tables 1-4. According to the literature data supported by the results of own research, in these areas of the examined steel after long-term annealing there occur mainly $\mathrm{M}_{6} \mathrm{C}$ carbides including $\mathrm{M}_{23} \mathrm{C}_{6}$ carbides for T23 and T24 low-alloy steels [19-22], while for P91 and P92 high-chromium steels there are $\mathrm{M}_{23} \mathrm{C}_{6}$ and Laves phase precipitates $[23,24]$.

The detailed description of changes in the microstructure of the examined steels in the as-received condition and after prolonged exposure to temperature and stress is presented in $[19,20,23,24]$.

Data analysis was performed for the examined steels with the aim of calculating a forecast of the probability density function. The analytical form of this function was selected to be the log-normal distribution [25]. It has two parameters: expected value and dispersion, which were estimated from the data collected. On this basis, the regression function parameters were estimated. Then the levels of the expected value and dispersion were calculated for the moment the forecast applied to. It has allowed the forecast probability density to be estimated.

The calculated log-normal distribution parameters became the basis for estimation of parameters of the linear regression function, which was used to develop a forecast for longer times 

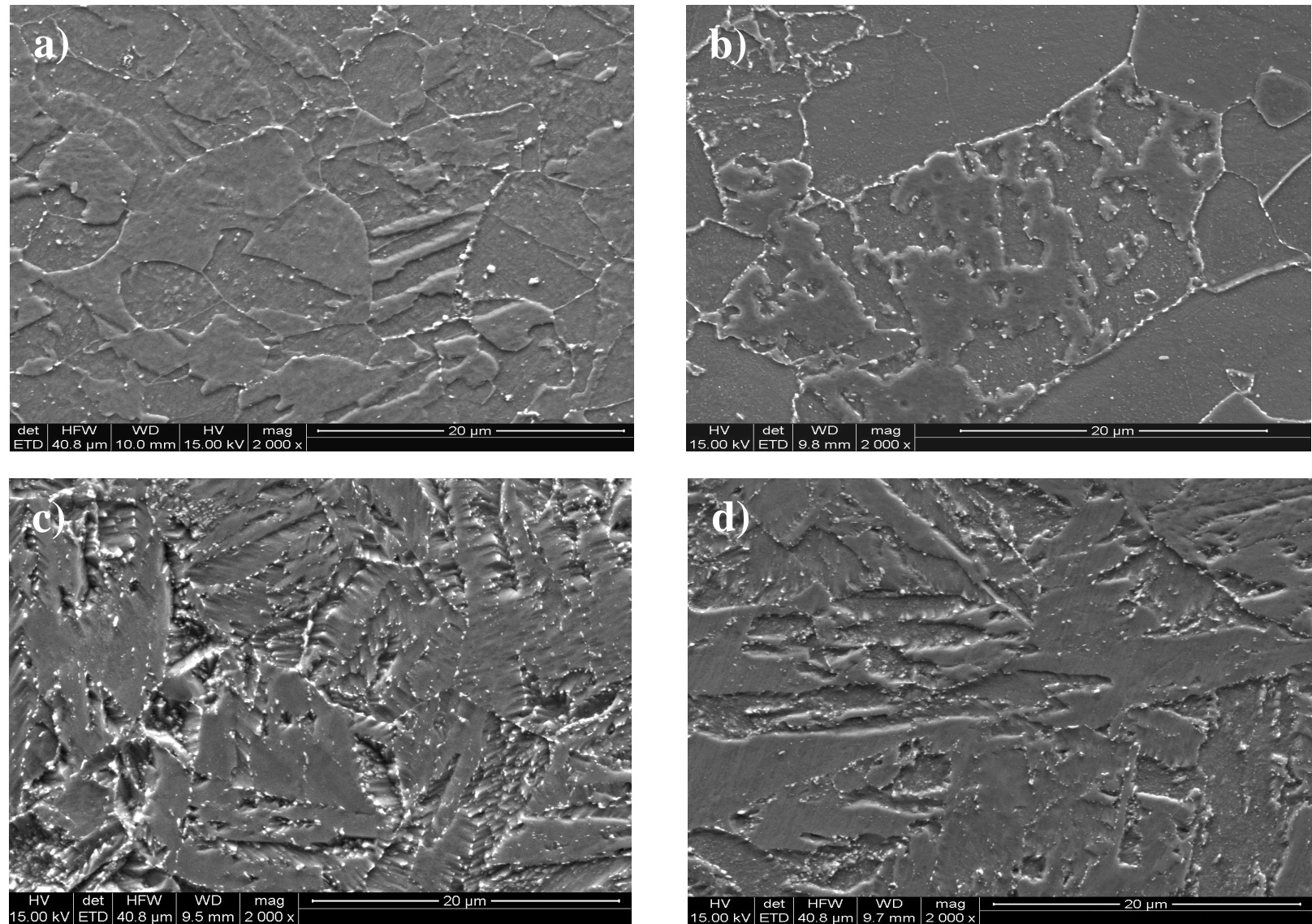

Fig. 1. Microstructure of the examined steels in the as-received condition: a) T23, b) T24, c) P91, d) P92, SEM
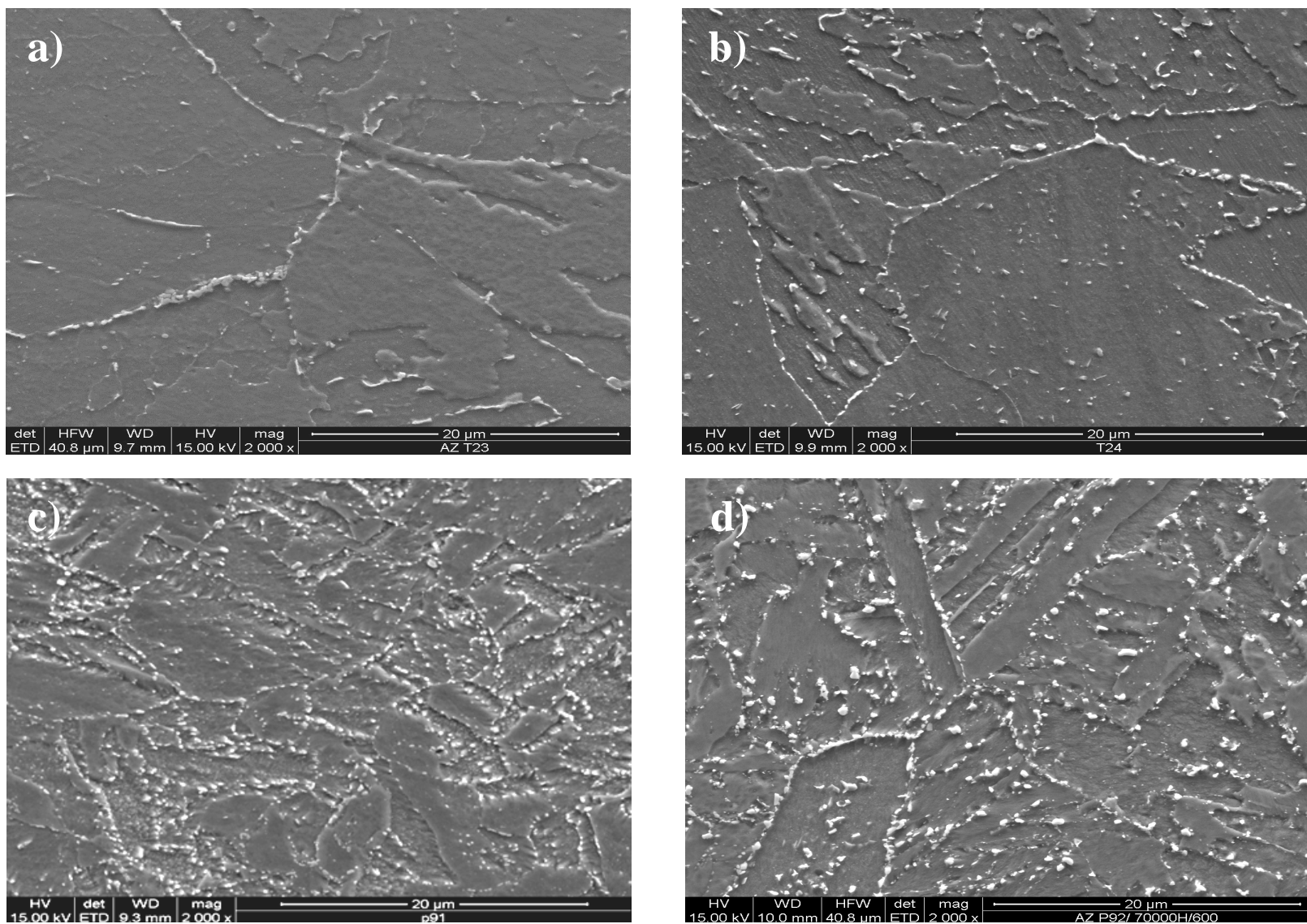

Fig. 2. Microstructure of the examined steels after $70.000 \mathrm{~h}$ annealing: a) T23, b) T24 at $550^{\circ} \mathrm{C}$, c) P91, d) P92 at $600^{\circ} \mathrm{C}, \mathrm{SEM}$ 


\section{6}
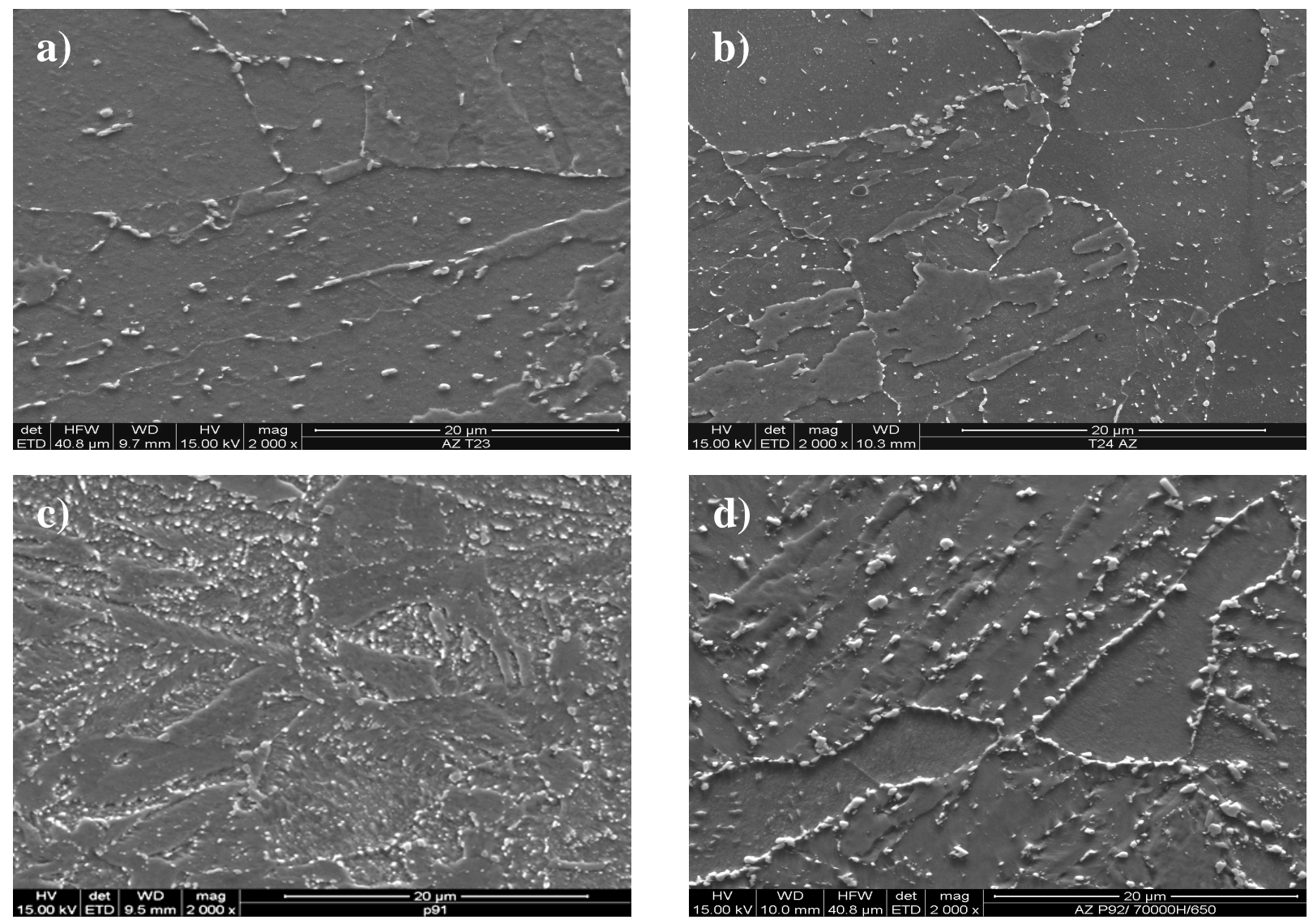

Fig. 3. Microstructure of the examined steels after $70,000 \mathrm{~h}$ annealing: a) T23, b) T24 at $600^{\circ} \mathrm{C}$, c) P91, d) $\mathrm{P} 92$ at $650^{\circ} \mathrm{C}, \mathrm{SEM}$

TABLE 1

Statistical measures describing the data set structure for T23 steel

\begin{tabular}{|c|c|c|c|c|c|c|c|c|}
\hline \hline Material condition & Average & St. dev. & Var. Coeff. & Skewness & Kurtosis & Quart. 1 25\% & Median 50\% & Quart. 2 75\% \\
\hline $550^{\circ} \mathrm{C} / 10^{3} \mathrm{~h}$ & 0.379 & 0.127 & $33.5 \%$ & 1.320 & 5.07 & 0.285 & 0.349 & 0.443 \\
\hline $550^{\circ} \mathrm{C} / 10^{4} \mathrm{~h}$ & 0.355 & 0.161 & $45.4 \%$ & 2.560 & 12.05 & 0.263 & 0.315 & 0.401 \\
\hline $550^{\circ} \mathrm{C} / 7 \times 10^{4} \mathrm{~h}$ & 0.387 & 0.134 & $34.6 \%$ & 1.333 & 5.55 & 0.285 & 0.363 & 0.452 \\
\hline $600^{\circ} \mathrm{C} / 10^{3} \mathrm{~h}$ & 0.419 & 0.146 & $34.8 \%$ & 1.168 & 4.48 & 0.312 & 0.385 & 0.488 \\
\hline $600^{\circ} \mathrm{C} / 10^{4} \mathrm{~h}$ & 0.430 & 0.144 & $33.5 \%$ & 1.176 & 4.92 & 0.334 & 0.396 & 0.492 \\
\hline $600^{\circ} \mathrm{C} / 7 \times 10^{4} \mathrm{~h}$ & 0.557 & 0.187 & $33.6 \%$ & 1.544 & 5.53 & 0.423 & 0.508 & 0.633 \\
\hline $550^{\circ} \mathrm{C} / 10^{3} \mathrm{~h}$ & 0.661 & 0.245 & $37.1 \%$ & 1.075 & 4.05 & 0.469 & 0.607 & 0.803 \\
\hline
\end{tabular}

TABLE 2

Statistical measures describing the data set structure for T24 steel

\begin{tabular}{|c|c|c|c|c|c|c|c|c|}
\hline \hline Material condition & Average & St. dev. & Var. Coeff. & Skewness & Kurtosis & Quart. 1 25\% & Median 50\% & Quart. 2 75\% \\
\hline As-received & 0.159 & 0.061 & $38.7 \%$ & 1.069 & 3.540 & 0.110 & 0.143 & 0.191 \\
\hline $550^{\circ} \mathrm{C} / 10^{3} \mathrm{~h}$ & 0.175 & 0.064 & $36.6 \%$ & 0.639 & 3.004 & 0.127 & 0.163 & 0.216 \\
\hline $550^{\circ} \mathrm{C} / 10^{4} \mathrm{~h}$ & 0.193 & 0.078 & $40.4 \%$ & 0.788 & 3.551 & 0.135 & 0.180 & 0.243 \\
\hline $550^{\circ} \mathrm{C} / 7 \times 10^{4} \mathrm{~h}$ & 0.220 & 0.095 & $43.2 \%$ & 0.887 & 3.594 & 0.142 & 0.201 & 0.278 \\
\hline $600^{\circ} \mathrm{C} / 10^{3} \mathrm{~h}$ & 0.193 & 0.080 & $41.4 \%$ & 1.092 & 3.992 & 0.127 & 0.174 & 0.234 \\
\hline $600^{\circ} \mathrm{C} / 10^{4} \mathrm{~h}$ & 0.230 & 0.085 & $37.0 \%$ & 1.489 & 5.332 & 0.172 & 0.207 & 0.269 \\
\hline $600^{\circ} \mathrm{C} / 7 \times 10^{4} \mathrm{~h}$ & 0.271 & 0.095 & $35.1 \%$ & 1.260 & 5.169 & 0.202 & 0.257 & 0.319 \\
\hline
\end{tabular}

of annealing. The estimated levels of the mean of logarithms of analyzed variables $(\mu)$ and the standard deviation of logarithms of variables $(\sigma)$ for the examined steel are shown in Table 5. They became the basis for estimation of parameters of the regression function, which was then used to calculate a forecast of these parameters for specified time of service. Knowing these forecasts, the probability density functions were estimated for log-normal distribution at given moments. These functions are shown in the figures. Thus, changes in the microstructure were described using the probability density functions. 
TABLE 3

Statistical measures describing the data set structure for P91 steel

\begin{tabular}{|c|c|c|c|c|c|c|c|c|}
\hline \hline Material condition & Average & St. dev. & Var. Coeff. & Skewness & Kurtosis & Quart. 1 25\% & Median 50\% & Quart. 2 75\% \\
\hline as-received & 0.172 & 0.073 & $42.4 \%$ & 1.535 & 6.503 & 0.119 & 0.156 & 0.207 \\
\hline $600^{\circ} \mathrm{C} / 10^{3} \mathrm{~h}$ & 0.237 & 0.084 & $35.4 \%$ & 1.069 & 3.97 & 0.174 & 0.221 & 0.278 \\
\hline $600^{\circ} \mathrm{C} / 10^{4} \mathrm{~h}$ & 0.271 & 0.106 & $39.1 \%$ & 0.757 & 2.803 & 0.186 & 0.247 & 0.343 \\
\hline $600^{\circ} \mathrm{C} / 7 \times 10^{4} \mathrm{~h}$ & 0.309 & 0.097 & $31.4 \%$ & 0.854 & 3.695 & 0.238 & 0.289 & 0.361 \\
\hline $650^{\circ} \mathrm{C} / 10^{3} \mathrm{~h}$ & 0.234 & 0.087 & $37.2 \%$ & 0.991 & 3.705 & 0.168 & 0.211 & 0.289 \\
\hline $650^{\circ} \mathrm{C} / 10^{4} \mathrm{~h}$ & 0.289 & 0.125 & $43.3 \%$ & 1.409 & 5.291 & 0.196 & 0.255 & 0.351 \\
\hline $650^{\circ} \mathrm{C} / 7 \times 10^{4} \mathrm{~h}$ & 0.356 & 0.134 & $37.6 \%$ & 1.646 & 7.232 & 0.259 & 0.319 & 0.416 \\
\hline
\end{tabular}

TABLE 4

Statistical measures describing the data set structure for P92 steel

\begin{tabular}{|c|c|c|c|c|c|c|c|c|}
\hline \hline Material condition & Average & St. dev. & Var. Coeff. & Skewness & Kurtosis & Quart. 1 25\% & Median 50\% & Quart. 2 75\% \\
\hline As-received & 0.178 & 0.061 & $34.3 \%$ & 0.765 & 3.010 & 0.127 & 0.162 & 0.216 \\
\hline $600^{\circ} \mathrm{C} / 10^{3} \mathrm{~h}$ & 0.287 & 0.146 & $50.9 \%$ & 1.355 & 4.761 & 0.180 & 0.247 & 0.355 \\
\hline $600^{\circ} \mathrm{C} / 10^{4} \mathrm{~h}$ & 0.320 & 0.159 & $49.7 \%$ & 1.426 & 5.506 & 0.202 & 0.276 & 0.404 \\
\hline $600^{\circ} \mathrm{C} / 7 \times 10^{4} \mathrm{~h}$ & 0.337 & 0.166 & $49.3 \%$ & 1.179 & 4.218 & 0.207 & 0.296 & 0.416 \\
\hline $650^{\circ} \mathrm{C} / 10^{3} \mathrm{~h}$ & 0.316 & 0.155 & $49.1 \%$ & 1.448 & 5.339 & 0.199 & 0.274 & 0.380 \\
\hline $650^{\circ} \mathrm{C} / 10^{4} \mathrm{~h}$ & 0.342 & 0.185 & $54.1 \%$ & 1.519 & 5.697 & 0.212 & 0.281 & 0.432 \\
\hline $650^{\circ} \mathrm{C} / 7 \times 10^{4} \mathrm{~h}$ & 0.352 & 0.181 & $51.3 \%$ & 1.433 & 6.141 & 0.212 & 0.306 & 0.449 \\
\hline
\end{tabular}

TABLE 5

Calculated log-normal distribution parameters for the examined steels

\begin{tabular}{|c|c|c|c|c|c|c|c|}
\hline \multicolumn{8}{|c|}{ T23 steel } \\
\hline & As-received condition & $550^{\circ} \mathrm{C} / 10^{3} \mathrm{~h}$ & $550^{\circ} \mathrm{C} / 10^{4} \mathrm{~h}$ & $550^{\circ} \mathrm{C} / 7 \times 10^{4} \mathrm{~h}$ & $600^{\circ} \mathrm{C} / 10^{3} \mathrm{~h}$ & $600^{\circ} \mathrm{C} / 10^{4} \mathrm{~h}$ & $600^{\circ} \mathrm{C} / 7 \times 10^{4} \mathrm{~h}$ \\
\hline$\mu$ & -1.02 & -1.11 & -1.00 & -0.92 & -0.89 & -0.63 & -0.48 \\
\hline$\sigma$ & 0.30 & 0.37 & 0.32 & 0.33 & 0.32 & 0.29 & 0.35 \\
\hline \multicolumn{8}{|c|}{ T24 steel } \\
\hline & As-received condition & $550^{\circ} \mathrm{C} / 10^{3} \mathrm{~h}$ & $550^{\circ} \mathrm{C} / 10^{4} \mathrm{~h}$ & $550^{\circ} \mathrm{C} / 7 \times 10^{4} \mathrm{~h}$ & $600^{\circ} \mathrm{C} / 10^{3} \mathrm{~h}$ & $600^{\circ} \mathrm{C} / 10^{4} \mathrm{~h}$ & $600^{\circ} \mathrm{C} / 7 \times 10^{4} \mathrm{~h}$ \\
\hline$\mu$ & -1.90 & -1.80 & -1.73 & -1.60 & -1.72 & -1.52 & -1.35 \\
\hline$\sigma$ & 0.35 & 0.37 & 0.42 & 0.43 & 0.39 & 0.32 & 0.32 \\
\hline \multicolumn{8}{|c|}{ P91 steel } \\
\hline & As-received condition & $600^{\circ} \mathrm{C} / 10^{3} \mathrm{~h}$ & $600^{\circ} \mathrm{C} / 10^{4} \mathrm{~h}$ & $600^{\circ} \mathrm{C} / 7 \times 10^{4} \mathrm{~h}$ & $650^{\circ} \mathrm{C} / 10^{3} \mathrm{~h}$ & $650^{\circ} \mathrm{C} / 10^{4} \mathrm{~h}$ & $650^{\circ} \mathrm{C} / 7 \times 10^{4} \mathrm{~h}$ \\
\hline$\mu$ & -1.8302 & -1.4955 & -1.377 & -1.222 & -1.5152 & -1.319 & -1.089 \\
\hline$\sigma$ & 0.3777 & 0.3324 & 0.383 & 0.311 & 0.357 & 0.3924 & 0.3338 \\
\hline \multicolumn{8}{|c|}{ P92 steel } \\
\hline & As-received condition & $600^{\circ} \mathrm{C} / 10^{3} \mathrm{~h}$ & $600^{\circ} \mathrm{C} / 10^{4} \mathrm{~h}$ & $600^{\circ} \mathrm{C} / 7 \times 10^{4} \mathrm{~h}$ & $650^{\circ} \mathrm{C} / 10^{3} \mathrm{~h}$ & $650^{\circ} \mathrm{C} / 10^{4} \mathrm{~h}$ & $650^{\circ} \mathrm{C} / 7 \times 10^{4} \mathrm{~h}$ \\
\hline$\mu$ & -1.78 & -1.36 & -1.24 & -1.19 & -1.25 & -1.19 & -1.16 \\
\hline$\sigma$ & 0.33 & 0.46 & 0.45 & 0.46 & 0.44 & 0.48 & 0.47 \\
\hline
\end{tabular}

\section{Conclusions}

Long-term annealing of the examined steels allowed for the quantitative description of changes in the microstructure at $550^{\circ} \mathrm{C}$ and $600^{\circ} \mathrm{C}$ for $\mathrm{T} 23$ and $\mathrm{T} 24$ low-alloy steels and at $600^{\circ} \mathrm{C}$ and $650^{\circ} \mathrm{C}$ for $\mathrm{P} 91$ and $\mathrm{P} 92$ high-chromium steels.

The quantitative analysis of selected microstructure images allowed to develop a database of precipitate diameters measured at two temperature values and in a few conditions, i.e. in the asreceived condition and following different times of long-term annealing. The collected results of investigations became the basis for performing statistical analysis of the set structure. It was demonstrated that the structure was changing in time, which was ultimately described by changes in parameters of the prob- ability density function. The formal description was made by mathematical statistics methods and using the theory of forecasting. The probability density function in the form of a log-normal distribution, described by a formula, was fit to the real average precipitate diameter distributions. The function parameters, i.e. the mean of logarithms of analyzed variables $(\mu)$ and the standard deviation of logarithms of variables $(\sigma)$, became the basis for estimation of parameters of the linear regression function, which was used to make a forecast of average diameter of precipitates and their distribution for longer times of annealing.

The performed statistical analysis of the increase in size of precipitates at a temperature similar to temperature of longterm service, i.e. $550^{\circ} \mathrm{C}$ for low-alloy steels and $600^{\circ} \mathrm{C}$ for high-chromium steels, indicates the continuous, yet very slow 


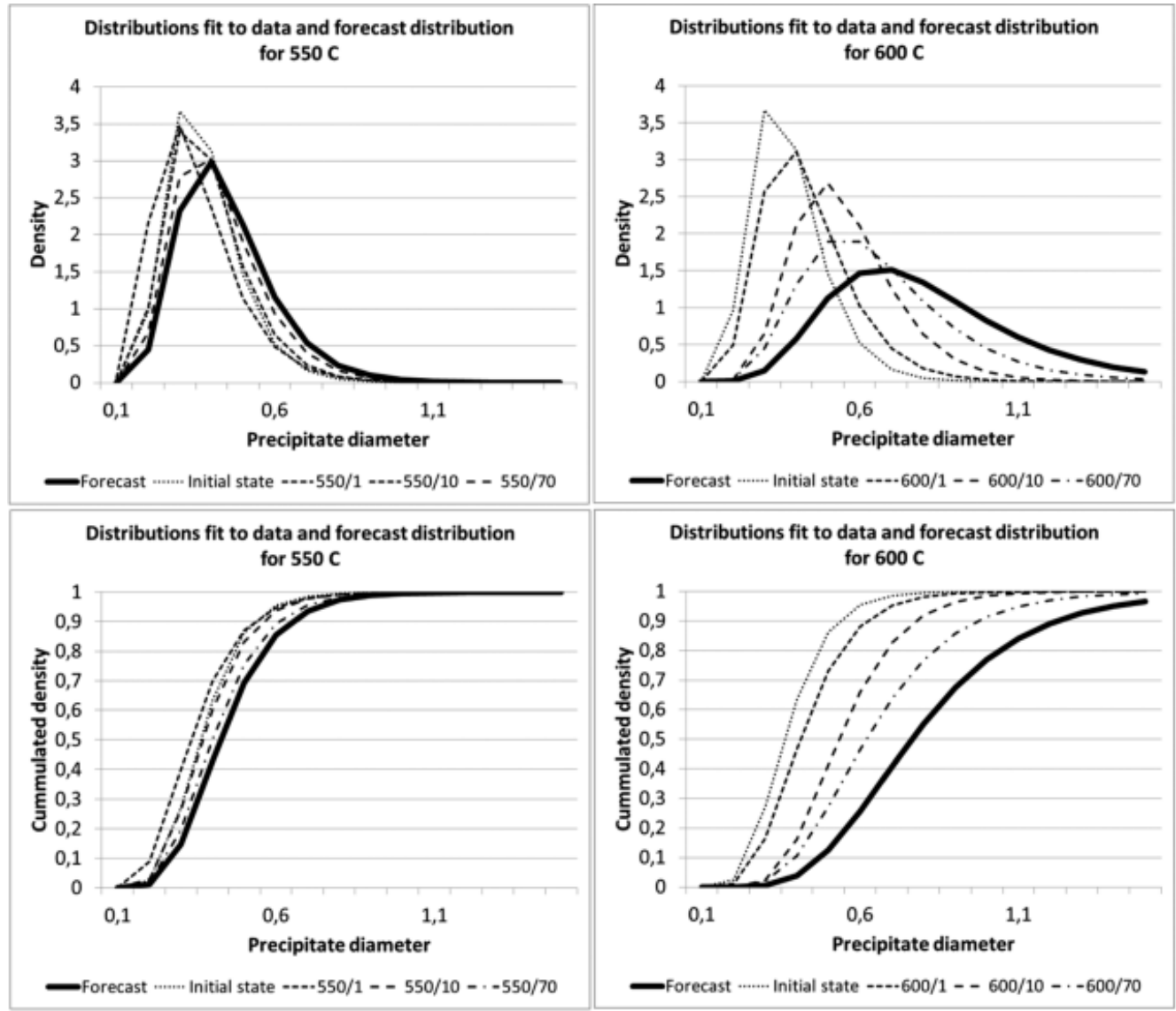

Fig. 4. Fit and forecast log-normal distributions of precipitate diameter in T23 steel

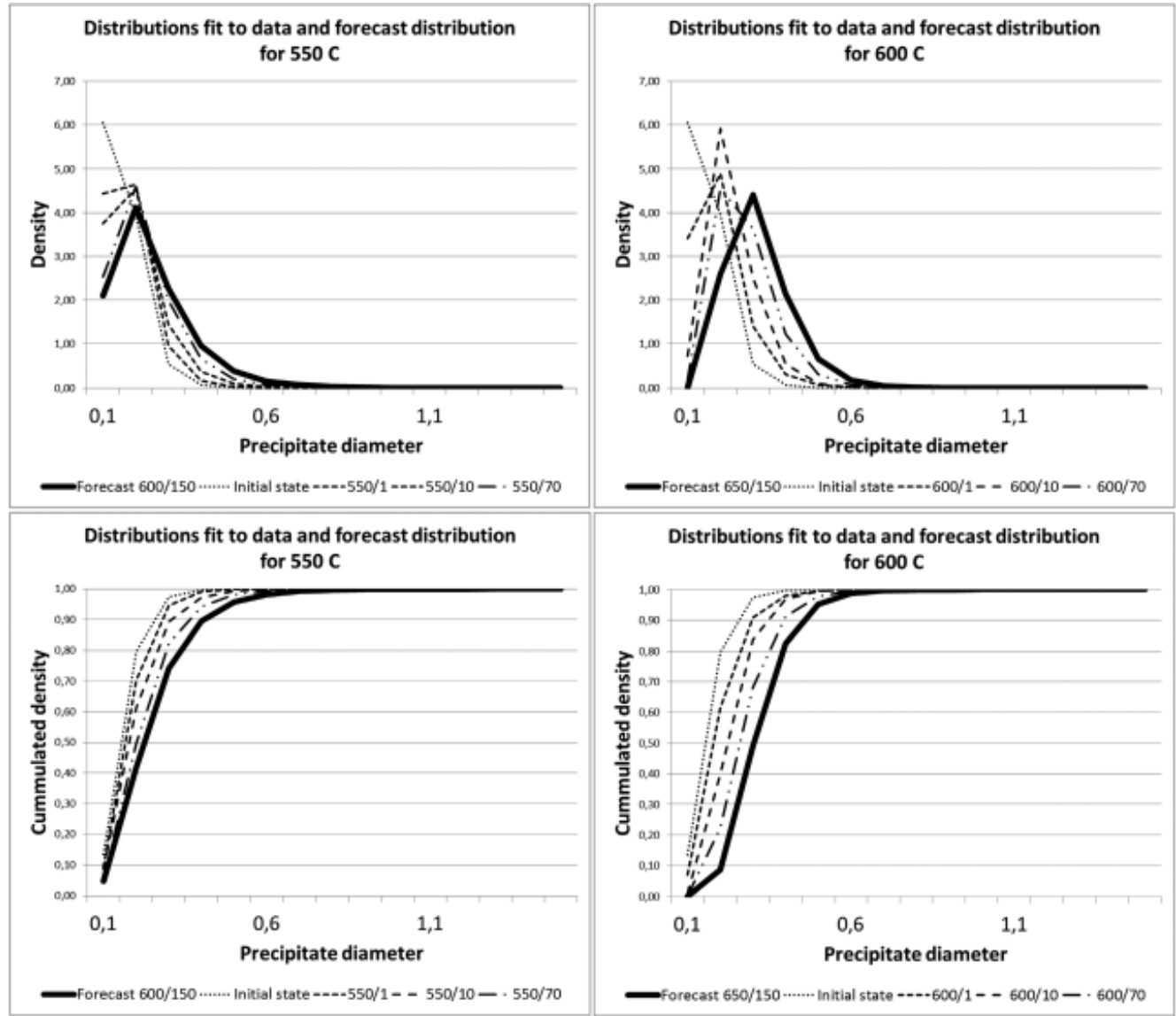

Fig. 5. Fit and forecast log-normal distributions of precipitate diameter in T24 steel 


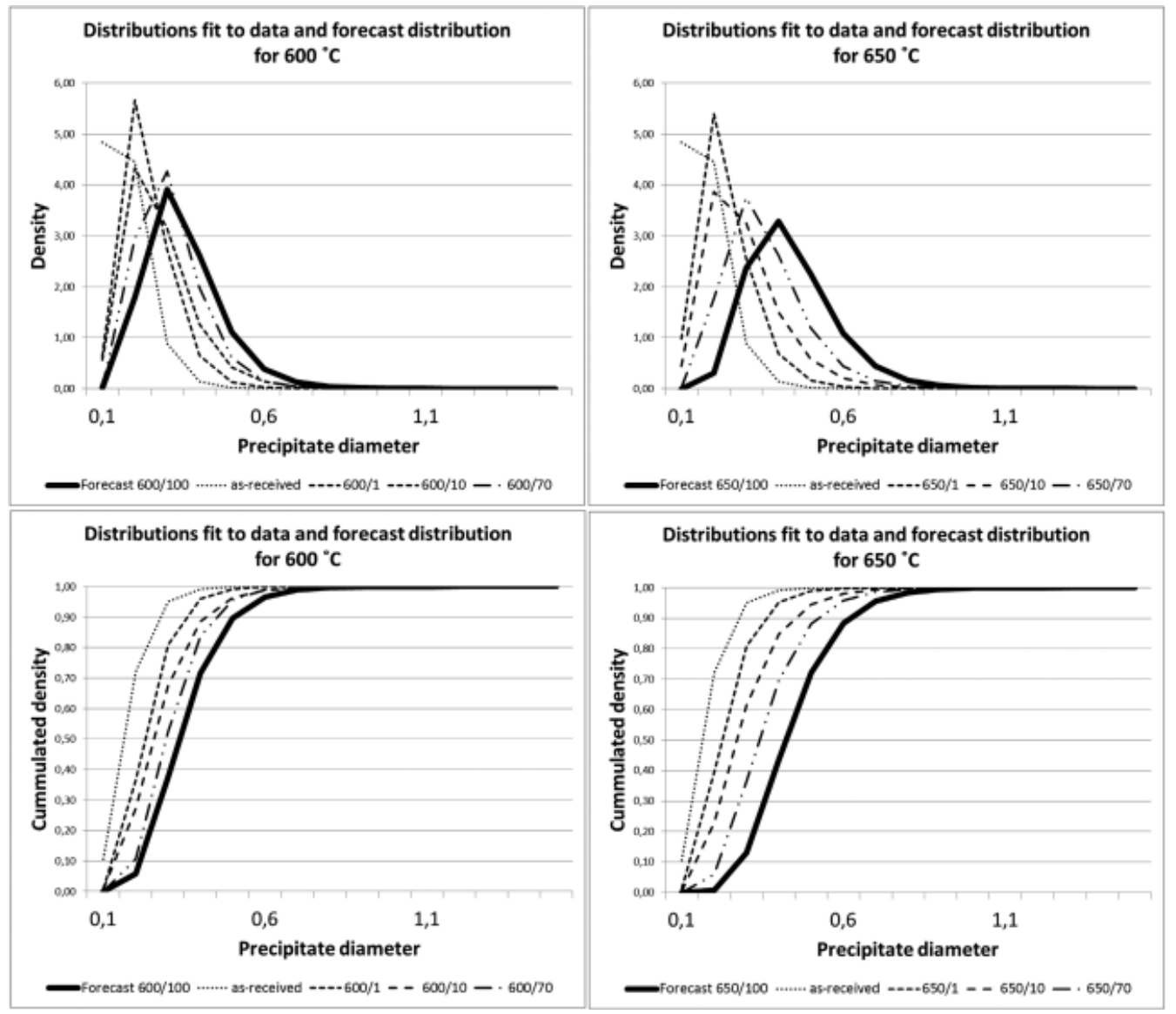

Fig. 6. Fit and forecast log-normal distributions of precipitate diameter in P91 steel

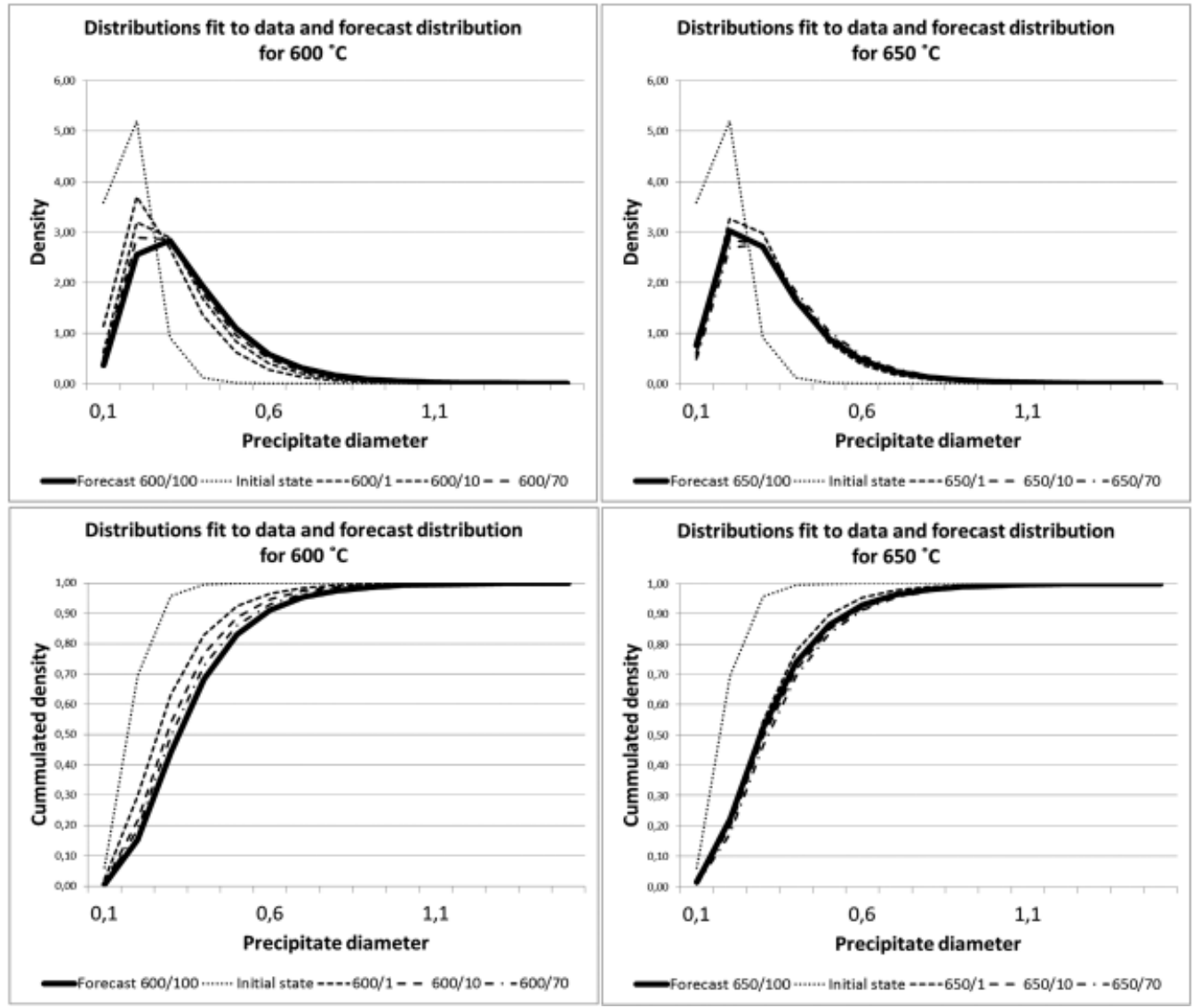

Fig. 6. Fit and forecast log-normal distributions of precipitate diameter in P92 steel 
growth of precipitates, whereas raising the annealing temperature to $600^{\circ} \mathrm{C}$ for low-alloy steels and $650^{\circ} \mathrm{C}$ for high-chromium steels revealed a significant increase in the growth dynamics of precipitates, which affects the reduction in their performance.

The calculated probability density function parameters (Table 5) indicate the possibility of comparing average precipitate diameters and their parameters depending on the annealing temperature. Such a similarity makes it possible to apply, in evaluation of the degradation degree of materials in use, the forecast by analogy methods.

\section{REFERENCES}

[1] P. Duda, Ł. Felkowski, J. Dobrzański, H. Purzyńska, Mater. High Temp. 33, 1, 85-93 (2016).

[2] J. Dobrzański, Open Access Library, Materials science interpretation of the life of steels for power plants, Gliwice 2011.

[3] P. Duda, D. Rząsa, Int. J. Energ. Res. 36 (6), $703-709$ (2012).

[4] J. Kępa, G. Golański, A. Zieliński, A. Brodziak-Hyska, J. Vibroeng, 14 (1), 143-150 (2012).

[5] P. Duda, Int. J. Mech. Sci., 107, 201-214. (2016).

[6] A. Hernas, J. Dobrzański, Life-time and damage of boilers and steam turbines elements, Publishing House of The Silesian University of Technology, Gliwice 2003

[7] A. Zieliński, M. Miczka, B. Boryczko, M. Sroka, Arch. Civ. Mech. Eng. 4, 813-824 (2016).

[8] A. Zieliński, G. Golański, M. Sroka, J. Dobrzański, Mater. Sci. Tech-Lond. 32 (8), 780-785 (2016).

[9] G. Golański, A. Zieliński, A. Zielińska-Lipiec, Materialwiss. Werkst. 46 (3), 248-255, (2015).

[10] W. Yan, W. Wang, Y.Y. Shan, K. Yang, Front. Mater. Sci. 7, 1-27 (2013).
[11] H. Adrian, J. Augustyn-Pieniążek, P. Marynowski, P. Matusiewicz, Hutnik, Wiadomości Hutnicze 81, (4), 208-214 (2014).

[12] S.M. Ross, Introduction to Probability and Statistics for Engineers and Scientists, Elsevier (2014).

[13] G.E.P. Box, G.M. Jenkins and G.C. Reinsel, Time series analysis, forecasting and control, Wiley, (2008).

[14] M. Fisz, Probability theory and mathematical statistics, John Wiley and Sons, (1980).

[15] Z. Gong, W. Dingand and B. Wang, Heat Treat. Met. 4, 78-81 (2013).

[16] G. Golański, A. Zieliński, J. Słania and J. Jasak, Arch. Metall. Mater. 59 (4), 1350-1354 (2014).

[17] A. Zieliński, G. Golański, M. Sroka, T. Tański, Mater. High Temp. 33 (1), 24-32 (2016).

[18] A. Zieliński, M. Miczka, M. Sroka, Mater. Sci. Tech-Lond. 32 (18), 1899-1910 (2016).

[19] A. Zieliński, G. Golański, M. Sroka, P. Skupień, Mater. High Temp. 33 (2), 154-163 (2016).

[20] A. Zieliński, G. Golański, M. Sroka, Mat. Sci. Eng. A-Struct. 682, 664-672 (2017).

[21] K. Rodak, A. Hernas, A. Kiełbus, Characteristics of new low-alloy steel T23 for power industry. In: Proc. 10th Jubilee International Scientific Conference Achievements in Mechanical \& Materials Engineering, Gliwice, Cracow, 483-486 Zakopane, Poland. (2001).

[22] L. Wang, L. Zhu, Y. Deng, Q. Wang, F. Zou, High Temp. Mater. Proc. 27 (1), 11-18 (2008).

[23] A. Zieliński, G. Golański, M. Sroka, Kovove Mater. 54 (1), 61-70 (2016).

[24] A. Zieliński, A., J. Dobrzański, Archives of Materials Science and Engineering 60, 72-81 (2013).

[25] M. Fisz, Probability theory and mathematical statistics, 1980, Hoboken, NJ, John Wiley and Sons. 